\title{
An Explanatory Study on Management Quality, Innovation and Long Term Orientation Towards Company Performance in Malaysia
}

\author{
Mashaal Abdullah Mohammed Saif, Ibiwani Alisa Hussain, Noraini Ahmad" \\ Faculty of Business and Management, Asia Pacific University of Technology and Innovation, Kuala Lumpur, Malaysia
}

Email address:

Mashaal.saif@gmail.com (M. A. M. Saif), ibiwani@apu.edu.my (I. A. Hussain), noraini@apu.edu.my (N. Ahmad)

${ }^{*}$ Corresponding author

\section{To cite this article:}

Mashaal Abdullah Mohammed Saif, Ibiwani Alisa Hussain, Noraini Ahmad. An Explanatory Study on Management Quality, Innovation and Long Term Orientation towards Company Performance in Malaysia. International Journal of Law and Society.

Vol. 1, No. 2, 2018, pp. 77-83. doi: 10.11648/j.ijls.20180102.14

Received: November 17, 2017; Accepted: February 6, 2018; Published: March 2, 2018

\begin{abstract}
The study aims to investigate the relationship between quality of management, innovation and long term orientation towards company performance in high performing organisations in Malaysia. Using convenience based sampling methods authors have used quantitative methodology, where total set of $n=120$ questionnaires have been distributed amongst top 30 high performing organisations listed in Bursa Malaysia. Authors have used statistical package for social sciences (SPSS) to conduct data analysis using descriptive and inferential statistics. Descriptive statistics has been used to conduct demographic analysis of respondents catered by researcher to ensure adequate sampling techniques, whereas inferential statistical analysis has been conducted to make analysis for the variables included in the study. Authors have used Pearson correlation and multiple regression analysis to interpret the results. The research findings reveal that only innovation and long term orientation has significant relationship towards company performance in high performing organisation in Malaysia, whereas quality of management is not significant towards company performance in high performing organisations.
\end{abstract}

Keywords: Quality of Management, Innovation, Long Term Orientation, High Performing Organisation

\section{Introduction}

Management is an important driver of high organization performance as it is responsible for the coordination of organizational resources to provide goods and service to clients in exchange of value [1]. Management drives organizational performance by analysis business situation, making decision and implementing decision by taking action to create and sustain organizational competitive advantage [2]. Organization performance is all about achieving organization related outcomes in context of strategic goals, customer satisfaction and economic contributions. Management is a life line of organization irrespective of size to ensures that organization performs exceptionally while achieving its tactical, operational and strategic goals by means of organizing, controlling, directing coordinating and leading [3].

Increase in demand from company stakeholder have created immense pressure on management to achieve competitive advantage on the basis of price, quality, flexibility, delivery times, and after sales support [4]. These elements are the means of achieving competitive advantage, which differentiates high performing organizations (HPO) from their other counterparts. High performing organizations (HPO) are companies, which are accountable, adaptive, agile, flexible, reliable, robust and sustainable entities [4]. Performing driven organizations as an enterprise which differentiates itself from other organizations in the context of financial performance, high productivity, innovation, leadership and satisfied internal and external customers [5].

Many studies, such as [4]; [2]; [3] have validated the role of management quality as the most important and foremost attribute of high performing organization (HPO). Quality of management aims to maintain the equilibrium in the organization by creating trust worthy correlation between all stakeholders in the organization. Per [4] quality management in organization aims to facilitate all stakeholders, which includes employees, shareholders and suppliers to achieve 
the goals by communication organizational values and strategy. High performing organization (HPO) aims to combine technical, conceptual and skilful traits of planning, organizing, leading and controlling under the umbrella of leadership. Management coordinates work related activities by building trust relationships at all organizational levels to achieve organization vision and mission. Quality of management has thus emerged as an important driver of high performing organization (HPO).

Many authors, such as [6]; and [7] have investigated the relationship of innovation in driving performance of high performing organizations (HPO). As innovation strategy always helps in getting better ways that enable firms to come up with the most appropriate knowledge base, in which firm may or may not get involved of their own R\&D investment. One of the most important tool for organisations to develop process and product is utilising the IT innovations. As improvement in the IT of the firms usually help in formulating strategies that provide guidelines for using innovative utility of information technology for the purpose of reducing operational cost and enhancing productivity. The ultimate goal in having innovation strategy is most likely enhancing the firms' performance, for instance, implementing innovative strategies that focus on increasing in profitability and growth [8]. Firms performance scope is then influenced by the level of innovation output mainly, the process and products, thus any improvement in the firms' performance would be a result of a successful implementation for the innovation output (process and products) at right place on the right time. Therefore, firms' strategies in innovating in the product and process are crucial key factors in the enhancement of the competitive edge of the firms. This mainly because these innovative strategies would alter firms' product portfolio to further enhance the demand curve that resulted from the betterquality features of the innovative products, which is distinguished from pervious products. By this economic phenomenon, innovative firms can gain a bigger market share and enter into an era of high performing organization (HPO) [6].

Many researchers, such as [4]; [9] have investigated the role of long term orientation (LTO) and high organization performance. The concept of long term orientation (LTO) aims to underpin the commitment of all stakeholders towards long term gains. Stakeholders include internal customers, external customers, suppliers and society in larger perspective. Using the notion of long term orientation organizations aims to enhance creation of customer value to learn what customer really wants, so firms can establish long term relationship and focus continuously on enhancement of customer value [4].

In order to investigate the factors influencing high performing organization in context of Malaysia, this research tends to examine the role of quality of management, innovation and long term orientation on company performance to achieve the status of high performing organization. Hence, this study is targeting top 30 performing companies from Kuala Lumpur Stock exchange, which has highest market capitalization and highest financial performance. This Study has featured on middle level managers working on different managerial positions in the selected firms using convenience based sampling techniques, as the study is purely quantitative in nature supported by collection of primary data.

\section{Literature Review}

There is no universal definition for High performing organization (HPO), however it has been defined differently by different authors. Furtermore, [10] defined HPO as a "creative, flexible and high performing learning organization which outperforms other organizations to achieve competitive advantage."

Per [4] compiled 280 studies to differentiate HPO with non HPO, his results have suggested that all the HPO have outperformed non HPO in the perspective of financial and operational performance. As this improvement in financial and operational performance is gained through attaining higher customer satisfaction and loyalty, employees loyalty, and introducing better quality of products and services. Furthermore, [4] has found that HPO has 10\% higher revenue growth, $29 \%$ high profitability, $2 \%$ high return on assets, $17 \%$ high return on equity, $20 \%$ high return on investment and 23\% higher shares return than non HPO. [11]; and [4] also analysed key drivers of HPO which included management quality, openness to action orientation, long term orientation, continuous improvement and workforce quality. They have witnessed significant differences across profit and non-profit organization, however strategy does not play an important role as there are distinctive factor in the uniqueness of the strategy compared to competitors in the same industry.

\subsection{Quality of Management and High Performing Organizations}

Components of quality management as leadership commitment, process management, and communication and information sharing should be explored to achieve high competitive performance [12]. Moreover [13]; and [14] analysed managerial roles requires by HPO or high commitment organization. They further state that there are seven essential managerial roles which are pre-requisite to achieve the status of HPO. Authors state that first management of HPO must entail a clear sense of purpose and direction by having meaningful vision and mission. Second, management must emphasis on developing a sense of urgency to meet the diverse needs and preferences of customers. Third, management must encourage open system in organization which fosters institutionalize continuous improvement and innovation. Fourth, management must encourage diverse culture and teamwork while treating everyone as a business partner. Fifth, demonstrate to employees that work is life. Sixth, invest in people by providing them with adequate tools, training, knowledge and 
skills and seventh, eliminating barriers to success.

\subsection{Innovation and High Performing Organizations}

Lam (2011) defines innovation as a "non-routine, significant, and discontinuous organizational change that embodies a new idea that is not consistent with the current concept of the organization's business". Therefore, HPO are usually those innovative organisations, which are ready to change and improve in their process and products strategies with a precise, intelligent and creative policies that make them capable of learning effectively and efficiently from the new knowledge and advancement in their respective industries. Beside that, [15] further suggested that innovation strategies are key factors that influence HPO due to their enhancement of the organisations growth and competitive advantage.

Beside that, [16] revealed that the innovativeness of organisations has a positively correlation with firm performance. They further explained that this positive influence result in bringing a competitive advantage for those organisations. As those organisations are commitment to learning through building a full understanding of customer needs, competitors' actions, and technological development. Furthermore, [17] made important distinctions between innovative and non-innovative firm based on the intensity, orientation and persistence on their innovation activities, type and novelty at the rate of their product innovation that are taken up by the market. Their finding stated that novel product innovator is more innovative intensive than non-novel innovators, so investing higher proportion of turnover on $R \& D$ such as technologist or scientists produce favourable results. They further stated that novel innovators tend to report high proportion of sales consisting of new product and lower proportion of sales consisting of upgraded products. However novel innovators have less reliance on input from suppliers and customers as compared to non-novel innovators. In terms of policy implications, it seems clear that transfer of knowledge and skills are likely to promote frequency and extent of innovative activity. In their recommendations, it was stated that deployment of graduates in organization is likely to create positive impact on firm's capacity as it creates exchange of information and transfer of technology between universities and firms.

\subsection{Long Term Orientation and High Performing Organization}

Furtermore, [18] in their study identified long term orientation as an important dimension of organization culture which provides distinct advantage for firms to outperform other competitors. [2] defined long term orientation LTO as "a tendency of an organization to prioritize the long-range implications and impact of decisions and actions that come to fruition after an extended time period". [4] stated that long term orientation is the commitment of organization extended towards all primary and secondary stakeholders, which includes both internal and external customers such as clients, investors, employees, suppliers and community. High performing organization achieves LTO by enhancing value to all stakeholders by achieving the expected needs and preferences of customers, building long term relationship with clients, timely engaging them while continuously enhancing customer value. It is essential for HPO to develop long term relationship with all networking stakeholders to create a win win relationship [4]. Management of a HPO is committed to the organization performance for the long run by balancing common purpose with self-interest, and teaching organizational members to put the needs of the enterprise as a whole first. HPO grow new management from their own ranks by encouraging people to become leaders, filling positions with internal talent, and promoting within the employees of their own organization. HPO also creates a safe and secure workplace by giving people a sense of safety (physical and mental) and job security and by not immediately laying off people (until it cannot be avoided, as a last resort).

\section{Methodology}

The objective of the study is to determine the relationship of management quality, innovation and long terrn orientation towards company performance in high performing organization in Malaysia. Researchers have used quantitative techniques of data collection to investigate the correlation of management quality, innovation and long term orientation towards company performance in high performing organization. Primary data was gathered primarily using survey questionnaires. Researchers have used convenience based sampling method as 180 questionnaires targeted on top 30 high ranked performing organization on Bursa Malaysia or Kuala Lumpur Stock Exchange. This study primarily has targeted on top corporations, which have the highest market capitalization, irrespective of their private or public structure. Authors have mainly targeted middle level managers as a cluster for sampling, because they are the best source of information with their diverse influence in their respective organizations. Out of 180 questionnaires, only 120 were complete, as it was difficult for researchers to gather more questionnaires due to the limitation of being able to reach to the respondents (middle level managers).

\subsection{Instrumentations}

Authors have used questionnaires, in which the correlation of dependent variable with independent variables would be measured. To avoid the invalidity of the questionnaire, authors have not create the questionnaires and instead questioners in this research have been adopted from previous studies as this would help in getting more reliable questionnaires. This research is measuring the adapted questionnaires utilising Likert scale that is implementing five measurement levels that are between strongly agree to strongly disagree. All the items in this research are in a positive statement. Each item has been evaluated as 
"Strongly agree, Agree, Neither, Disagree, Strongly disagree". The scoring processes were A 5-point interval Likert scale of 1 denoting strongly disagree and 5 strongly agree. The instrumentations have been adapted from the previous studies of [4] and [19]. As all of the items can be seen in the below table 1 .

Table 1. Measurements Items.

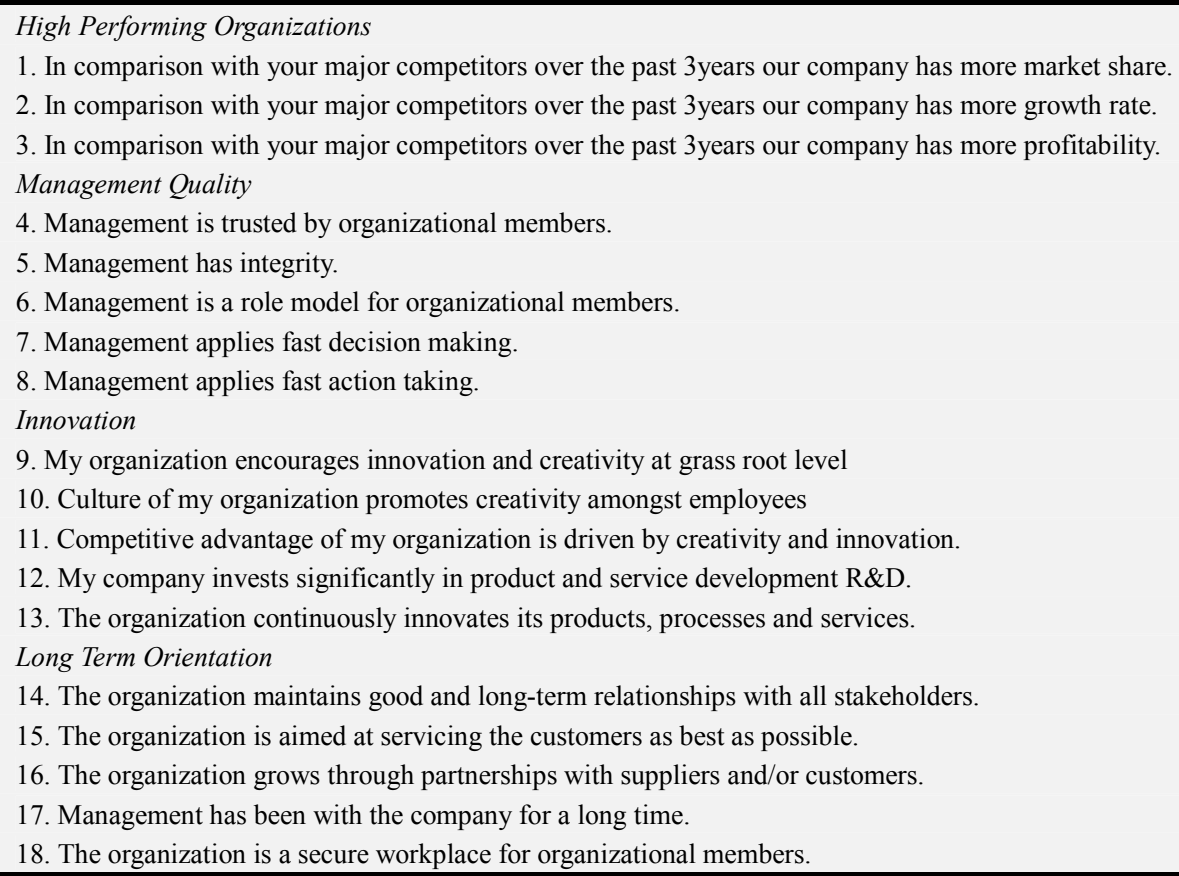

\subsection{Data Analysis Technique}

Researchers have used quantitative data, which has been collected from surveys using convince sampling method. Analysis in this research has been done through utilising statistical application SPSS. The proposed hypothesis has been tested and analysed by using statistical tools. Researchers have developed descriptive statistics of the respondent's profile, which enable them to check the quality of response gathered using convenience based sampling technique. In order to ensure that respondents are from the selected target audience, which is middle level managers from the selected 30 listed companies from bursa Malaysia. Furthermore, researchers have used inferential statistics of Pearson correlation, and multiple regression analysis method to investigate the drivers of HPO in context of Malaysia.

\subsection{Reliability of Questionnaires}

According to [20], reliability test is a tool that help in measuring the consistency of primary data collected via questionnaires. Hence, this research has conducted this test to fulfil the reliability and validity of the questionnaires. Hence, if the Cronbach's Alpha obtained scored 0.7 and above it is considered highly reliable. The below table 2 provide the summary of Cronbach's Alpha obtained in this research. Results suggested that management quality and innovation are moderately reliable scale with 0.6.11 and 0.635 respectively, however scale for long term orientation is highly reliable with score of 0.710 .
Table 2. The Results of Reliability Test for the variables.

\begin{tabular}{lll}
\hline Variable & Cronbach's Alpha & Remark \\
\hline Management Quality & 0.611 & Moderately reliable. \\
Innovation & 0.635 & Moderately reliable. \\
Long Term orientation & 0.710 & Highly reliable. \\
\hline
\end{tabular}

\section{Findings}

Demographics of respondents showed that out of the targeted 120 respondents 55\% were male and remaining $45 \%$ were female. This shows that authors have targeted different clusters from the sample population. Regarding the respondents age groups, 5\% belonged to the age group of 26 to 30 years old, $50.8 \%$ belonged to the age group of 31 to 35 years old, which are the majority, $29.2 \%$ belonged to the age group of 36 to 40 years old, $10.8 \%$ belonged to the age group of 41 to 45 years old, lastly remaining $4.2 \%$ belonged to the age group of 46 and above years old. Regarding the respondents position in their respective organizations, $15.8 \%$ were finance managers, $23.3 \%$ were marketing managers, $20.8 \%$ were supply chain managers, $20 \%$ were human resource managers, $18.3 \%$ were customer service managers, lastly $1.7 \%$ belonged to other managerial level position. Regarding the working period of the respective organisations, $35.8 \%$ were working for $2-3$ years, $50.8 \%$ were working for 3-4 years, $13.3 \%$ were working for more than 5 years, lastly, none of the respondents catered in the survey were working in their respective organisations for less than one year. Finally, regarding the academic background, majority of respondents, which is $84.2 \%$ have a 
master degree, 9.2\% have bachelor's degree, remaining $6.7 \%$ have doctorate degree, lastly, none of the respondents have diploma certification.

Pearson's correlation analysis was conducted in order to examine the correlation between IV (1) management quality, IV (2) innovation, and IV (3) long term orientation with (DV) company performance. From the results obtained, it can be observed that all the independent variables are correlated with the dependent variable, but with different level of correlation. As the output shows that IV (1) management quality is weakly correlated with company performance in high performing organization (HPO) in Malaysian context with the positive coefficient value of $\mathrm{r}=0.479$, IV (2) innovation is strongly correlated with company performance in high performing organization (HPO) in Malaysian context with the positive coefficient value of $\mathrm{r}=0.608$, IV (3) long term orientation is also strongly correlated with company performance in high performing organization (HPO) in Malaysian context with the positive coefficient value of $\mathrm{r}=0.593$ as it can be seen in the following Table 3.

Table 3. Pearson Correlation.

\begin{tabular}{llll}
\hline VARIABLES & Company performance & Management Quality & Innovation \\
\hline High Performing Organization & 1 & & \\
Management Quality & $.479 * *$ & 1 & 1 \\
Innovation & $.601^{* *}$ & $.684^{* *}$ & $.711^{* *}$ \\
Long Term Orientation & $.593^{* *}$ & $.681^{* *}$ & 1 \\
\hline
\end{tabular}

**Correlation is significant at the 0.01 level (2-tailed).

Multiple Regression Analysis also was conducted to investigate the significant of the correlation between IV (1) management quality, IV (2) innovation, and IV (3) long term orientation with (DV) high performing organization in the Malaysian context. The outputs are as following:

Table 4. Model Summary.

\begin{tabular}{lllll}
\hline Model Summary & & & \\
\hline Model & $\mathrm{R}$ & $\mathrm{R}$-Square & Adjusted R-Square & Std. Error of the Estimate \\
1 & $.652^{\mathrm{a}}$ & .425 & .410 & .28262 \\
\hline
\end{tabular}

a. Predictors: (Constant), LTO, Innovation, Management Quality.

Table 4 above shows that the coefficient determination $(\mathrm{R}$ square $)=0.425$. It represents that management quality, innovation, and long term orientation have contributed to $42.5 \%$ towards company performance in high performing organization in the Malaysian context. However, the remaining 57.5\% (100-42.5\%) is classified as the elastic factors that are uncontrollable.

Table 5. ANOVA Analysis.

\begin{tabular}{|c|c|c|c|c|c|c|}
\hline \multicolumn{7}{|c|}{ ANOVA $^{a}$} \\
\hline & & Sum of Squares & df & Mean Square & $\mathbf{F}$ & Sig. \\
\hline \multirow{3}{*}{1} & Regression & 6.845 & 3 & 2.282 & 28.565 & $.000^{\mathrm{b}}$ \\
\hline & Residual & 9.265 & 116 & .080 & & \\
\hline & Total & 16.110 & 119 & & & \\
\hline
\end{tabular}

a. Dependent Variable: Company Performance.

b. Predictors: (Constant), LTO, Innovation, Management Quality.

Based on Table 5 above, the $F$ value is 28.565 is significant at the level of $0.000(p<0.05)$. Hence, the overall regression model for management quality, innovation, and long term orientation is working properly in explaining company performance in high performing organization in Malaysian context.

Table 6. Coefficients

\begin{tabular}{|c|c|c|c|c|c|c|c|c|c|}
\hline \multicolumn{10}{|c|}{ Coefficients $^{a}$} \\
\hline \multirow{2}{*}{\multicolumn{2}{|c|}{ Model }} & \multicolumn{2}{|c|}{ Unstandardized Coefficients } & \multirow{2}{*}{$\begin{array}{l}\text { Standardized Coefficients } \\
\text { Beta }\end{array}$} & \multirow{2}{*}{$\mathbf{t}$} & \multirow{2}{*}{ Sig. } & \multicolumn{3}{|c|}{ Correlations } \\
\hline & & $\mathrm{B}$ & Std. Error & & & & Zero-order & Partial & Part \\
\hline \multirow{4}{*}{1} & (Constant) & .914 & .403 & & 2.267 & .025 & & & \\
\hline & Mgmt Quality & -.044 & .127 & -.038 & -.348 & .729 & .479 & -.032 & -024 \\
\hline & Innovation & .445 & .121 & .383 & 3.668 & .000 & .601 & .322 & .258 \\
\hline & LTO & .402 & .121 & .359 & 3.315 & .001 & .593 & .294 & .233 \\
\hline
\end{tabular}

a. Dependent Variable: Company Performance.

From Table 6 above, management quality influence on company performance in HPO has found to be insignificant 
influence $(\mathrm{p}=0.729>$ Sig. $5 \%)$, thus this variable has been rejected. However, innovation has a significant positive influence on company performance in HPO in the Malaysian context. The data are $\mathrm{t}=3.668, \mathrm{p}=0.000, \beta=0.45$. If Innovation increased by one unit, it will increase the company performance in HPO by 0.45 as well. Finally, long term orientation has a significant positive influence on company performance in HPO in the Malaysian context. The data are $\mathrm{t}=3.315, \mathrm{p}=0.001, \beta=0.402$. If long term orientation increased by one unit, it will increase the company performance in HPO in the Malaysian context by 0.402 as well.

Furthermore, Table 6 above shows that Beta for total quality management is -0.038 which is the lowest Beta value, therefore quality management is the lowest indicator that made the lowest of a unique contribution to explain company performance in HPO, thus rejecting this variable. However, Beta value for the other variables innovation and long term orientation (LTO) are 0.383 and 0.359 respectively, therefore they are making strong indicators of unique contributions to explain the company performance in HPO. Hence, those variables have been accepted.

\section{Conclusion}

Findings of inferential statistics indicates that innovation and long term orientation are strongly positive correlated with company performance in high performing organization (HPO) with the correlation coefficient value $r=>0.5(r=0.601$ and $\mathrm{r}=0.593$ respectively), however management quality is weakly correlated with company performance in high performing organization (HPO) with the correlation coefficient value less than $\mathrm{r}=<0.5(\mathrm{r}=0.479)$. Regression analysis was conducted to predict the significant impact of successful traits of company performing, whereby findings indicates that only innovation and long term orientation are significant predictors of company performance in high performing organization. The research findings are validated the findings of previous empirical evidence of [16], [15], [9], [6], [7] and [4], whereas rejecting [14] and [3] findings.

Research findings indicates that innovation and long term orientation are significant predictors of company performance in high performing organization in Malaysia only if it complimented by adequate organization design, strategy, process management, technology, leadership, organization culture and external orientation. Both innovation and long term orientation have organizational and managerial implications, which compliment high performing organization. High performing organization (HPO) must possess continuously propagated strategy which creates balance between long term and short term focus. Despite having a clear strategic orientation in the vision and mission, the strategy must compliment the demands and needs of external environment and customer orientation. Thus, HPO must adapt strategies which can set company apart by developing new options and alternatives to compensate for dying strategies. Leadership role and transition can have significant implications on high performing organization (HPO). Leadership in HPO must not be vulnerable to change; instead leadership should motivate change in process, people and technology. [21] defines leaders of HPO as an "agent of Shifting/Transitioning individuals, teams, and organizations from a current state to a desired future state. It is an organizational process aimed at helping change stakeholders to accept and embrace changes in their business environment." Organization culture is the most valuable asset to drive long term orientation and innovativeness in high performing organization. [4] found that high performing organization (HPO) must possess a culture of empowerment and autonomy, so members of the organization have authority and freedom to act by devolving decision making authority. Leaders must establish clear, strong and meaningful core values to develop performance driven culture so organization can achieve high excellence. Beside that culture of high performing organization must prevail norms of transparency, openness, trust, shared understanding and openly sharing information. Finally, as the study has revealed that management quality is not a significant predictor of company performance in HPO in the Malaysian context, it is a notable clue for Malaysian firms to re-check on the management quality policies and tasks. This is because, many studies, such as [4]; [2]; [3] have validated the role of management quality as the most important and foremost attribute of high performing organization (HPO). As the management coordinates work related activities by building trust relationships at all organizational levels to achieve organization vision and mission.

\section{References}

[1] American Management Association. (2007). How to build a High-Performance Organization. A Global Study of Current Trends and Future Possibilities 2007-2017. New York: AMA.

[2] Liberman, L., \& Boehe, D. (2011). Worldwide willingness to delegate and country labor quality. The International Journal of Human Resource Management, 22 (17), 3477-3495.

[3] Sunday, K. J., \& Somoye, R. O. C. (2011). Organization Performance: The Roles and the Duties of Managers. Journal of African Macroeconomic Review, 1 (1), 33, 54.

[4] Waal, A. A. (2008). The secret of high performance organizations. Management Online Review, (April).

[5] Epstein, J. L., Williams, K. J., \& Jansorn, N. R. (2004). Does policy prompt partnerships? Effects of NCLB on district leadership for family involvement. In annual meeting of the American Educational Research Association, San Diego, CA.

[6] Schmiele, A., \& Rammer, C. (2008). Drivers and Effects of Internationalising Innovation by SMEs (No. 08-035). ZEW Discussion Papers.

[7] Vrgovic, P., Vidicki, P., Glassman, B., \& Walton, A. (2012). Open innovation for SMEs in developing countries-An intermediated communication network model for collaboration beyond obstacles. Innovation, 14 (3), 290-302. 
[8] Hult, G. T. M., Hurley, R. F., \& Knight, G. A. (2004). Innovativeness: Its antecedents and impact on business performance. Industrial marketing management, 33 (5), 429438.

[9] Lumpkin, G. T., Brigham, K. H., \& Moss, T. W. (2010). Long-term orientation: Implications for the entrepreneurial orientation and performance of family businesses. Entrepreneurship and Regional Development, 22 (3-4), 241264.

[10] Pasmore, W. A. (1994). Creating strategic change: Designing the flexible, high-performing organization. John Wiley \& Sons.

[11] Manzoni, J. F. (2004). From high performance organizations to an organizational excellence framework. Performance measurement and management control: Superior organizational performance, 19-45.

[12] Phan, A. C., Abdallah, A. B., \& Matsui, Y. (2011). Quality management practices and competitive performance: Empirical evidence from Japanese manufacturing companies. International Journal of Production Economics, 133 (2), 518529.

[13] Frick, B., \& Simmons, R. (2008). The impact of managerial quality on organizational performance: evidence from German soccer. Managerial and Decision Economics, 29 (7), 593-600.

[14] Kirkman, B. L., Lowe, K. B., \& Young, D. P. (1999). High-
Performance Work Organizations. Leadership in Action, 19 (2), 13-15.

[15] Lam, A. (2011, April). Innovative organisations: Structure, learning, and adaptation. In Paper presented at the DIME Final Conference (Vol. 6, p. 8).

[16] Calantone, R. J., Cavusgil, S. T., \& Zhao, Y. (2002). Learning orientation, firm innovation capability, and firm performance. Industrial marketing management, 31 (6), 515-524.

[17] Mbizi, R., Hove, L., Thondhlana, A., \& Kakava, N. (2013). Innovation in SMEs: A review of its role to organisational performance and SMEs operations sustainability. Interdisciplinary Journal of Contemporary Research in Business, 4 (11), 370-389.

[18] Gupta, A., McDaniel, J. C., \& Kanthi Herath, S. (2005). Quality management in service firms: sustaining structures of total quality service. Managing Service Quality: An International Journal, 15 (4), 389-402.

[19] Rhee, J., Park, T., \& Lee, D. H. (2010). Drivers of innovativeness and performance for innovative SMEs in South Korea: Mediation of learning orientation. Technovation, 30 (1), 65-75.

[20] Nunnally, J. C. (1978). Psychometric Theory (2nd Edit.) McGraw-Hill. Hillsdale, NJ.

[21] Kotter, J. P. (2008). Corporate culture and performance. Simon and Schuster. 